\title{
Instructional Materials Development in ODL: Achievements, Prospects and Challenges
}

\author{
Felix Gbenoba
}

\section{Opeyemi Dahunsi}

\author{
Directorate of Instructional Materials Development, National Open University of Nigeria, Lagos
}

\section{Doi:10.5901/jesr.2014.v4n7p138}

\section{Abstract}

Customised, self-instructional materials are at the heart of instructional delivery in Open and Distance Learning (ODL). The success of any ODL institution depends on the availability of learning materials in quality and quantity. An ODL study material is expected to imitate what the teacher does in the face-to-face learning environment. This paper evaluates these expectation based on existing data and evidence. It concludes that the reality has not matched the expectation so far in terms of pedagogic aspect of instructional delivery especially in West Africa. This does not mean that instructional materials development has not produced any significant positive results in improving the overall learning (and teaching) experience in these institutions; it implies what will help further to identify the new challenges. Obstacles and problems of instructional materials development that could have affected the open educational resource initiatives are well established. The first section of this paper recalls some of the proposed values of instructional materials. The second section compares achievements so far and suggests that instructional materials development should be consider first at an early stage to realise the aspirations of instructional delivery. The third section highlights the challenges of instructional materials development in the future.

Keywords: face-to-face learning; instructional delivery; Open and Distance Education; self-instructional materials.

\section{Introduction}

This paper examines the achievements, prospects and challenges of instructional materials development in ODL with particular reference to NOUN. ODL depends very much on customized self-instructional materials for learners. NOUN reflects these values in the provision of carefully designed self-learning instructional materials. These are also available in diverse formats including web interactive, web non interactive non-web, and non-interactive and braille options for visually impaired learners. The university has "a commitment to democratizing education by providing education to the physically challenged as well" (Awolalu, 2010).

The study suggests ways for increased access to course materials; tackling the challenges and meeting up with global best practices in the delivery of instructional materials.

Open and distance learning is one most revolutionary concept in the history of education. STRIDE/IGNOU (2000) defines distance education as that field of educational endeavour in which the learner is quasi-permanently separated from the teacher and learning group throughout the duration of the learning process; a technological medium replaces the interpersonal communication of conventional, oral group-based education; the teaching/learning process is institutionalized (thus distinguishing it from teach yourself programmes); and two-way communication is possible between both the student and the teacher (thus distinguishing it from other forms of educational technology). Nigeria as a nation has embraced ODL as an emerging mode of education delivery

Nigeria and many other developing countries have recognized ODL as a viable means of 'increasing educational access and educational choice', (COL, 2005) to meet the Millennium Development Goals (MDGs) particularly because of its potential for mass access to education. This led to the establishment of the National Open University of Nigeria (NOUN). By this revolutionary form of learning, students would enjoy the opportunity of working and learning at the same time, without one negatively affecting the other (Jegede, 2005). ODL has the potential for massive spread of higher education among a large number of Nigerians, who might otherwise find it difficult to attend conventional classes due to myriad constraints and challenges (Gambari, 2014). The idea of an open university for Nigeria, as a single mode institution was appropriately reflected in the National Policy on Education which stated emphatically and unambiguously that "maximum efforts will be given to enable those who can benefit from higher education to be given access to it. Such access may be through universities, correspondence courses, or open universities, or part-time and work study programme". As Ogunmakin puts it: 
It is meant to take care of the tertiary education needs of qualified Nigerians, who hitherto were precluded from fulfilling their desire for higher education because of age, full time employment, and limited capacity of available conventional universities to carry the teeming population of Nigerians, and other social circumstances, through the Open and Distance Learning (ODL) mode of instructional delivery (The Daily Independent, 19 July, 2013)."

NOUN was established because the carrying capacity of the face-to-face conventional tertiary institutions in Nigeria was insufficient. For instance, the Joint Admission and Matriculation Board (JAMB) received more than 1.5 million applications to Nigerian universities in 2009, but the facilities at the 96 universities in the country could not allow admission of more than $20 \%$ of this number (Jegede, 2009). No carrying capacity is set for NOUN's uper-limit admission. NOUN is Nigeria's only specialist provider of open and distance learning at the tertiary level. It is the country's largest tertiary institution in terms of number of students, and it operates from an administrative headquarters in Lagos, Nigeria, with Study Centres spread throughout the country.

NOUN's commitment to openness is shown as its effort in publishing all its courses as open courseware on its Web site (see http://www.nou.edu.ng/noun/NOUN_OCL/courses.htm). This can be seen as an equal opportunity university. Like its conventional counterparts, it is subject to the accreditation exercise put in place by the Federal Government of Nigeria through the National Universities Commission (NUC). The mode of instruction is the major difference between NOUN and conventional universities as (NOUN, 2007). The ODL mode is designed to provide students with the opportunity to acquire knowledge, skills, and techniques relevant to either their present work situation or future career prospects (Okonkwo, 2013).

\section{Self-Instructional Materials}

Customized, self-instructional materials (SIMs) are at the heart of instructional delivery in ODL. The success of any ODL institution depends on the availability of learning materials in quality and quantity. A good SIM is prepared to stimulate independent learning. They are therefore different from a chapter of a textbook or an article in a journal. In designing ODL materials, understanding learners' characteristics is very important. SIMs should be learner-oriented and should be specially designed according to the principles of self-instruction. What this means is that the learner should be able to learn with or without the support of the teacher. It should be self-explanatory, self-contained, self-directing, selfmotivating and self-evaluating. This is important because the learner often feels isolated in the absence of the teacher and peer-learners. Table 1 shows some major differences between self-instructional materials and conventional texts.

Table 1: Differences between SIM and Conventional Texts

\begin{tabular}{|c|c|}
\hline Textbooks & Self-Learning Materials \\
\hline - $\quad$ Assume interest & - $\quad$ Arouse interest \\
\hline - Written mainly for teacher use & - Written primarily for Learner use \\
\hline - Do not indicate study time & - $\quad$ Give estimates of study time \\
\hline - $\quad$ Designed for a wider market & - $\quad$ Designed for a particular learner group \\
\hline - $\quad$ Rarely state aims and objectives & - $\quad$ Always give aims and objectives \\
\hline - $\quad$ Structured for teachers and specialists & - $\quad$ Structured according to the need of learners \\
\hline - $\quad$ Little or no self-assessment & - $\quad$ Major emphasis on self-assessment \\
\hline - $\quad$ Seldom anticipates difficulties & - $\quad$ Alert to potential difficulties \\
\hline - $\quad$ Dense content and dense layout & - $\quad$ Content unpacked and more openly layout \\
\hline - $\quad$ Aims at scholarly presentation & - $\quad$ Aims at successful teaching \\
\hline - $\quad$ Can be read passively and no study skills advice & - $\quad$ Require active response and provide study skills advice \\
\hline
\end{tabular}

From the differences highlighted above, it can be deduced that self-learning materials play a vital role in distance learner's learning process.

\section{Instructional Delivery Strategies}

ODL course materials are specially designed, developed and written to fulfill its special purposes. NOUN provides course materials for its students using different media. These media have different attributes, and in any educational situation it 
is necessary to weigh the pros and cons of how best to deliver the educational message. Considerations of cost of production, students' access and ease of use are, in reality, as influential as educational effectiveness when deciding on the media mix for delivering the learning material. It is important to note that most instructional media are multifunctional and can be adapted to a wide range of purposes. In most instances, it makes sense to use the simplest, most accessible and most cost effective medium. Media options include: print, with text, illustrations, photographs, etc.; audio tape; videotape; multimedia; computer-aided learning; computer managed learning; communications technology/ e-learning platforms, for example, electronic mail, teleconference, computer conference or video conference; experimental kits (Awolalu, 2010).

Print is still a powerful medium in many open universities in developing as well as in developed countries (Gaba \& Dash, 2004). According to Jegede (2009), NOUN students depend mostly on the use of printed materials, and printed materials are expected to remain a major instructional mode until the infrastructure for total online teaching become available. Based on these, NOUN, besides using other media in the delivery of instruction to its students, depends so much on the printed course materials.

Process: The development of instructional material is carried out in the Directorate of Instructional Resources Development. As a first step, a Detailed Programme Proposal (DPP) is prepared by the Academic Planning Unit in collaboration with the Schools. This is subjected to the University Senate and the NUC approval. The course material is developed by a team comprising course developer, course writer, programme leader, course coordinator, instructional designer, content editor, and a graphic artist. NOUN adopts a 17- step Instructional Resources Development process, including: development of course, planning meeting, typesetting, formatting, editing, formative evaluation and query resolution, obtaining print quotations, print centre inspection, print centre approval, scripting, editing, commissioning non print delivery formats, delivery to store, uploading, publication announcement, summative evaluation, marking up copy for future review. All these processes are handled by certified professionals. A unique element in the Instructional Development process is the simultaneous production of both the print and non print delivery formats (Awolalu, 2010).

\section{Achievements}

Generally, NOUN has made some landmark academic achievements since its inception, this could not but be linked to the availability, accessibility and quality (both instructional and pedagogic) of self-learning instructional materials. Today, NOUN has on its courseware over 1600 course materials for its learners. These 1600 course materials are $53 \%$ available in printed format, $27 \%$ under printing while $30 \%$ are under processing and are to be made available for printing soon. It is important to note that almost $80 \%$ of these course materials have been printed before now and the figures given above are for those under processing for the current year. As at the university's third convocation in January, 2014, NOUN has graduated about 13,0000 students. Jegede (2010) observed that the "National Open University of Nigeria is today the largest university in Nigeria. Commencing academic activities in 2004 January, the university today has admitted close to 100,000 and registered students in her 92 programmes" (p. 155). Jegede also stated, "The university is in the process of developing about 982 course materials for students" (2010, p. 153). Today, the University has developed over 1600 course materials. As Tenebe 2014 also puts it:

...enrolment had continued to increase on daily basis with over 300,000 students currently studying at the ivory tower, promising to hit enrolment figure of 500,000 ahead of official target of 1.5 million students before he leaves office next year. (The Nigerian Tribune, July 21, 2014).

\section{Challenges}

As Igwe (2012) opines, NOUN cannot compete with many of the open universities, such as: United Kingdom Open University (UKOU), Indira Ghandi National Open University, India (IGNOU), Open University of South Africa, and Open University of Hong Kong in the area of availability of instructional materials. NOUN depends on print course materials and face-to-face facilitation which are meant as supplemental materials. Nigeria as a country is facing low level of development in Information and Communication Technology (ICT) facilities and support resources, including epileptic supply of electricity throughout the country that NOUN ought to serve.

The course materials are printed by NOUN through outsourcing. The contractors are delivering these materials to the University's central warehouse in Kaduna. The course materials are not evenly distributed as distance from the warehouse remains a challenge for the study centers.

The delivery mode in NOUN is still print-driven. This is unconnected with some associated difficulties in funding 
and technological advancement of the country. Unfortunately, the challenges of accessibility and poor distribution of course materials still linger (Jegede, 2009). Resolving the situation is critical for the progression of students and for the institution to fulfill its vision and mission. In February, 2011 NOUN's Senate targeted means of addressing the course material challenge after deliberating "on the pioneer students who had been in the university for about eight (8) years mainly due to non-availability of course materials ..." (Senate Decision Extract 3 cited in Okonkwo, 2012).

NOUN as an ODL institution does not provide lectures to her learners in a normal classroom situation, but instead provides specialized study materials that are based on self-learning. Each course has material written specifically for it, which students are expected to study prior to being examined. They are assessed mostly on the content of the materials for grades, leading to graduation and certification. These materials are written as lecture units or practical units (Okonkwo, 2013).

The three stages through which NOUN develop course materials for its students are:

- Development

- Production

- Distribution

The challenges would be discussed under each stage.

\section{The challenges associated with development}

Finding the right caliber of academics in the various subject areas to write course materials is a challenge if it were to be done wholly in-house. NOUN course materials are mostly developed from scratch; the written materials are processed inhouse as course content are expectedly aligned with the university's house style for uniqueness (Tseja et al, 2009). The house style of the institution guides the writers from start to finish. The institution has to hire and train writers (mostly from conventional universities) who are knowledgeable in the course content but are themselves, the product of conventional institution. Writing from scratch has not only resulted in huge financial outlay but challenges of time, getting appropriate venues, resource persons and support services have proved even more daunting. These resulted in the institution having several areas of attrition with almost all stakeholders in the business of teaching and learning via NOUN especially in the pioneering years.

It is also the practice with many ODL institutions to source course materials from other ODL institutions. Outsourcing can be a viable option because certain services or products are faster, easier, and cheaper to purchase than to produce from scratch. It also enables an institution to benefit from the expertise that is not available locally. NOUN, for example, has outsourced courses from IGNOU. Outsourcing is basically of two types:

Adoption: Adoption of a course refers to the process of changing aspects of an outsourced course material to meet the needs of your students and your institution. When the changes are more than $10 \%$ of the original material, the term adaptation is used. As a general rule, social science and arts courses outsourced from countries which have very marked differences in cultural and socio-political orientation from Nigeria may require radical adaptation, perhaps up to $50 \%$. This is because the examples used in such courses may not likely be understood within the country's cultural context. Secondly, the references cited or recommended books may not be easily accessible to students.

Adaptation: When the changes are less than $10 \%$ of the original, we use the term adaptation.

In both cases, adjustments have to be made to ensure that the course materials are suitable for NOUN students.

The process of developing ODL course materials is relatively time consuming and complicated as it moves back and forth between course team members especially between the course writer and the peer reviewer identified as course editor in the team list. Most of the course materials are produced in hard copy; some are burnt on CD, while some others are available on the other web and non-web formats.

There is always pressure on in-house course material writers and editors to submit write-ups within a limited time frame. In addition, irregular power supply and haphazard Internet access do not make the office environment conducive for the writing/development of course materials by academic staff. The office operates like a civil service office, where staff cannot work late because the university's facilities stop functioning adequately around 4 p.m. Therefore, working outside of scheduled official hours is not always feasible. Also, the skills of most writers/course developers need to be further honed with regards to writing SIMs. Most of the external writers are not technically trained in ODL and so they have difficulty putting materials together that adhere to NOUN's house style.

The power outages and the slow access to online sources are worsened by transportation and urban traffic problems take their toll on productivity, leading to substandard output (Okonkwo, 2013). 


\section{The challenges associated with production}

The challenges facing instructional materials production in NOUN are enormous despite several efforts of the institution's management through several innovations to make the course materials available and accessible in quality and quantity. At present, the in-house printing press of the University (Docutech) cannot meet up with two per cent of the requirement as a result of the over exploding population. The University cannot establish its own printing press due to huge amount required. Consequently, the University has been outsourcing the printing of course materials to printers. Before the present administration, it sometimes takes printers more than six months before the delivery but now printers are delivering within six weeks. The ever increasing in student populace equally requires reprinting of course materials to meet the demand and this could not be achieved without proper and adequate funding.

\section{The challenges associated with distribution}

On distribution, NOUN has about 52 study centres spread across the six geo-political zones of the country with only one course materials warehouse in Kaduna at present. The implication is that all the study centres have to travel to Kaduna to collect study materials for their students. This situation poses several challenges which could be encapsulated under three sub headings highlighted below:

- Distance

- Risk

- Cost of transportation, etc.

\section{Prospects of instructional materials development}

Going with the present trends, in the nearest future, print materials would be available for all the courses under all academic programmes of NOUN. Igwe (2012) posits that "when the needs are huge, fully online learning can be crucial and possibly the only realistic means to increase and rapidly widen access to tertiary education." Going by this assertion, it is pertinent to note that online learning stands to be the most realistic means of instructional delivery to ODL learners. NOUN as an ODL institution recently launched its e-learning platform (NOUNilearn). The essence is to revolutionize the delivery to meet the best global practices. E-learning is a promising tool for expanding and widening access to tertiary education. Because it relaxes space and time constraints, E-learning can easily admit new comers into ODL by increasing the flexibility of participation compared to the traditional face-to-face mode. In this way, working students and adults, people living in remote rural areas, non-mobile students, and even students outside the country could now more easily participate in education. With E-learning, learners can indeed study where and/or when they have time to do so, rather than where and/or when classes are planned (Igwe, 2012). While traditional correspondence-based distance learning has long played this role, ICTs have enhanced traditional distance education by enabling the rise of a continuum of practices between wholly campus-based education and wholly distance education. This approach to learning was developed taking into consideration the need for the learner to have flexible, affordable, accessible, and culturally relevant study materials.

\section{Recommendation}

While NOUN has been commended for efforts toward making instructional materials accessible and available both in quality and quantity to its learners, it is worthy to note that the objectives of the institution are yet to be fully realized. For further realization of the entire objectives as stated in NOUN's vision and mission, the university has make provision for the variety of instructional materials its entire programmes. NOUN equally has to increase the capacity of its faculty, and other relevant services solely for course material development and production. And increase its capacity in sourcing appropriate open education resources (which are abundantly available) and tailoring these materials to suit its learners needs.

NOUN has to dedicate adequate time to course material development and improve an environment that fosters international cooperation between her and the experienced faculties of other developed ODL institutions.

It is pertinent to state that operating a central warehousing system in an institution that is spread across the nooks and crannies of Nigeria is not the best. The paper therefore recommends the decentralization of the central warehouse to have one warehouse in each of the six geo-political zones of the country for easier distribution of instructional materials. 
These recommendations, if executed, would ensure the availability of the right professionals who could provide efficient ODL delivery. In fact, these recommendations are relevant for all developing countries, other ODL and intending institutions that are yet to embrace the ODL mode of instructional delivery.

\section{Conclusion}

Nigeria has adopted ODL because the low carrying capacity of its conventional tertiary institutions which has not been able to cater for its citizens' demand for higher education. NOUN operates within the context of admission requirements and the accreditation process put in place by the federal government of Nigeria through the NUC. SIMs remain the most important pedagogic tools in ODL and NOUN delivers these specialized self-learning materials through media-mix. Since the inception of the institution, the timely production of these self-instructional materials has been a challenge until recently when several innovations of the authority have started curbing the accessibility/availability challenges. NOUN has been graduating students as a result of these innovations and timeliness in the delivery of print materials by the printers. This paper has examined the process of developing SIMs at NOUN. Various obstacles in terms of availability, development, and distribution were identified while solutions were proffered as recommendation. Thus, the benefits of availability and accessibility through timely production instructional materials for NOUN students can be enumerated as:

- NOUN students have a fair chance to complete their programme of study on schedule

- conventional institutions have started using many of the course materials developed for NOUN students through the open courseware;

- more open content has become available for public assessment.

In the light of this, NOUN has increased the pace of educational delivery through accessibility and availability of learning materials both in quality and quantity.

\section{References}

Awolalu, T. (2010). Paper Presented at the Orientation Materials For Newly Appointed Study Centre Managers. Lagos: National Open University of Nigeria. pp. 154.

Commonwealth of Learning (2005). Creating Learning Materials for Open and Distance Learning: A Handbook for Authors and Instructional Designers. Canada: Commonwealth of Learning.

Gambari, I. A. (2014). "Open and Distance Education for Development, Unity and Democratic Transformation of Nigeria". Convocation Lecture at the 3rd Convocation ceremony, National Open University of Nigeria, Lagos.

Jegede, O. (2005). Training Manual on Course Material Development in Open and Distance Learning. Lagos: National Open University of Nigeria.

Jegede, O. J. (2009, July 4). The Vice Chancellor's message to the matriculating students. Speech delivered at NOUN's $4^{\text {th }}$ Matriculation Ceremony, NOUN Headquarters, Victoria Island, Lagos, Nigeria.

NOUN (2007). Getting to know your university: An orientation and information guide for students of National Open University of Nigeria. Lagos: National Open University of Nigeria.

Okonkwo, C. A. (2013). "Assessment of Challenges in Developing Self-Instructional Course Materials at National Open University of Nigeria." The International Review of Research in Open and Distance Learning.

Saide (2007). Open Learning Principles. Retrieved December 102008 from http://www.saide.org.za

Stride (2005). Development and Revision of self-Learning Materials. New Delhi: IGNOU.

Frederick Lockwood (1997). "Developing self-instructional Material for Open, Distance and Flexible." Pre ICDE Conference Workshop Report. Pennysylvania State University.

Gaba, A. K., \& Dash, N. K. (2004). Course Evaluation in Open and Distance Learning: A case study from Indira Gandhi National Open University. Open Learning, 19(2), 213-221.

Igwe, D. O. (2012). "The Roles of ICT Development in Open and Distance Education:acheivements, prospects and challenges." African Journal of Teacher Education. Vol 2, No 2 (2012).

Jegede, O. J. (2009, January 7). The beginning of a new dawn for education in Nigeria. Convocation speech delivered at NOUN's 1st Convocation Ceremony, NOUN Headquarters, Victoria Island, Lagos.

The Daily Independent, 19 July, 2013.

The Nigerian Tribune, July 21, 2014.

Tseja et al, (2009). Training Manual on Course Material Development in Open and Distance Learning. Lagos: National Open University of Nigeria. 